University of Nebraska - Lincoln

DigitalCommons@University of Nebraska - Lincoln

Long-Range Visibility of Greater Sage Grouse Leks: A GIS-Based Analysis

Andrea S. Aspbury

Texas State University - San Marcos, aspbury@txstate.edu

Robert M. Gibson

University of Nebraska - Lincoln, rgibson@unl.edu

Follow this and additional works at: https://digitalcommons.unl.edu/bioscifacpub

Part of the Life Sciences Commons

Aspbury, Andrea S. and Gibson, Robert M., "Long-Range Visibility of Greater Sage Grouse Leks: A GISBased Analysis" (2004). Faculty Publications in the Biological Sciences. 228.

https://digitalcommons.unl.edu/bioscifacpub/228

This Article is brought to you for free and open access by the Papers in the Biological Sciences at DigitalCommons@University of Nebraska - Lincoln. It has been accepted for inclusion in Faculty Publications in the Biological Sciences by an authorized administrator of DigitalCommons@University of Nebraska - Lincoln. 


\title{
Long-Range Visibility of Greater Sage Grouse Leks: A GIS-Based Analysis
}

\author{
Andrea S. Aspbury and Robert M. Gibson \\ School of Biological Sciences, University of Nebraska-Lincoln, Lincoln, Nebraska, USA \\ Article history: Received March 23, 2002; initial acceptance July 22, 2002; final acceptance June 13, 2003; Manuscript number: A9316)
}

\begin{abstract}
We investigated whether male greater sage grouse, Centrocercus urophasianus, select lek locations on the basis of topographic features that affect their visibility to both conspecific females and a major avian predator, the golden eagle, Aquila chrysaetos. We mapped locations of displaying males at all leks in a local population and used a Geographic Information System (GIS) and digital elevation model (DEM) to generate 'viewsheds' around male locations within a boundary set by the estimated maximal visual acuity of the viewer. Areas visible around leks were compared to those visible around random sites with the same conformation of displaying males. Male sage grouse displayed at sites where surrounding topography both diminished long-range visibility $(>1,000 \mathrm{~m})$ and enhanced short-range visibility $(<500 \mathrm{~m})$ to ground observers. These characteristics could (1) force eagles to monitor lek activity from the air, where they may be more visible to their prey, (2) make displaying males more visible to females and (3) allow males to monitor predators approaching the lek more easily. These results suggest that, in open habitats, visually signalling animals may exploit local topography to control both their visibility to receivers and the visibility of their immediate surroundings.
\end{abstract}

Sexual advertisement increases an animal's conspicuousness to both potential mates and predators (Andersson 1994; Zuk \& Kolluru 1998). This trade-off is particularly relevant to visual signals, which are accessible to a wide range of receivers and can be exactly localized (Bradbury \& Vehrencamp 1998). Predation costs associated with visual sexual advertisement may be reduced by several behavioral mechanisms. These include concealing signals except during display, avoiding light environments that enhance signal contrast and hence visibility except when displaying (Endler \& Théry 1996), and reducing long-range visibility by exploiting either concealing objects (Candolin \& Voight 1998) or local light environments (Heindl \& Winkler 2003) to reduce longer-range visibility to predators without impairing short-range visibility to prospective mates. Several of these options are particularly relevant to animals inhabiting heavily vegetated habitats where structural complexity both limits the range of vision and creates a complex mosaic of alternative light environments.

In open habitats with few visual barriers, visual signals are potentially detectable at longer ranges, and are limited by receiver visual acuity. In such habitats, however, the active space of a signal could still be constrained by topographic features that obstruct vision between receiver and signaller. This creates the potential for signalling animals to exploit local topog- raphy to make themselves either more or less visible to receivers. Because topography will also affect the visibility of potential receivers to signallers, the latter might also exploit local topography to control the visibility of their immediate surroundings. Although some of these possibilities have been raised previously (Wiley 1973), there appears to have been little formal study of the extent to which visually signalling animals exploit topography to limit their visibility to potential predators, enhance their visibility to prospective mates, or increase their ability to monitor approaching predators.

These scenarios may be particularly relevant to the greater sage grouse, Centrocercus urophasianus, a large, terrestrial, lek-breeding phasianid native to sagebrushsteppe habitats in western North America. Most lek displays in this species occur around dawn over a period of 6-8 weeks in early spring. At this time, males move from sagebrush scrub, where they are well concealed, into open areas where they become visually conspicuous due to their erect posture and exposure of white feathers, covering the inflated neck and breast, that contrast sharply with the mostly dark body plumage (Wiley 1973). Because of their large size, conspicuous behavior, and the openness of the habitat, lekking

Correspondence: A.S. Aspbury, Department of Biology, Texas State University-SanMarcos,SanMarcos,Texas,USA; aspbury@txstate.edu. 
males are potentially visible at long ranges to receivers with high visual acuity. These include both conspecifics and raptors, particularly the golden eagle, Aquila chrysaetos, the only diurnal raptor that regularly attacks and kills lekking males (Hartzler 1974; Bradbury et al. 1989b; Gibson \& Bachman 1992). Male sage grouse react with alarm to even the distant appearance of this predator (Hartzler 1974) and we have recently shown that they also reduce time on leks under conditions that increase the risk of attacks by eagles (Boyko et al. 2004). Golden eagle foraging behavior is highly variable but includes prey search both from perches and during low-level flights (Watson 1997; R.M. Gibson, unpublished data), both of which can be close enough to the ground to make topographic relief a constraint on the visibility of prey to the predator and vice versa. Because sage grouse are terrestrial, topography also poses a relevant constraint on their visual communication.

Previous studies indicated that the general, although not the specific, locations of greater sage grouse leks are predictable from patterns of female traffic during dispersal from wintering to nesting ranges (Bradbury et al. 1989a; Gibson 1996). Here we investigate whether males also select lek locations on the basis of topographic features that affect three potentially conflicting characteristics: (1) the visibility of males to perched or flying eagles, (2) the visibility of an approaching eagle to males at the lek and (3) the visibility of males to conspecific females. To investigate these questions, we used a Geographic Information System (GIS) and a digital elevation model (DEM) to generate 'viewsheds' around locations within a boundary set by the estimated maximal visual acuity of the viewer. We used this approach to compare the visibility of leks to that of random nonlek sites under alternative viewing scenarios.

\section{METHODS}

We studied a resident population of greater sage grouse in Long Valley, Mono County, California, USA, described by Bradbury et al. (1989b). We collected data on male locations on seven leks that were active during April 12-19, 2001.

We mapped males at each lek from known observation sites, using a Bushnell laser rangefinder and a Suunto compass to generate polar coordinates. These coordinates were converted to Universal Transverse Mercator (UTM) coordinates after determining observation locations with a global positioning system. At six of the seven leks, a single observer began scanning from left to right, collecting location data on every displaying male at intervals of $10-15 \mathrm{~min}$, from the time we could see males (approximately 0545 hours Pacific Standard Time) until light conditions made it diffi- cult to generate accurate distance data (approximately 0700 hours). Because the remaining lek was large (148 males), two observers positioned on opposite sides of the lek mapped grouse only along the lek perimeter. For the following analyses, we used the scan that corresponded to the peak number of mapped males at each lek (mean $=13.14$; range 3-47).

\section{Measuring Visibility}

We entered the UTM data for each male into ArcView GIS v3.1 and mapped the data onto a DEM consisting of an array of elevations for a grid of ground positions spaced at 30-m intervals (Figure 1). We modified the DEM by subtracting areas not normally used by sage grouse (forests and open water).

We calculated the area visible from a particular lek site as the number of grid cells in the DEM that could be seen from at least one male location. A line was drawn from each male location to each cell in the DEM, and the cell was considered visible if there was no other cell between the male and the focal cell that exceeded the line's elevation. This process was repeated for each cell in the elevation grid and for each male, and the output for each lek was a new grid with an associated summary table and values ranging from zero to $N$ ( $N=$ number of males). Specifying an outer search radius set the outer spatial extent of the analysis. In addition, offset heights could be added to both the focal points (displaying males in this case) and to the observer points (all other cells in the grid). For all analyses, we added an offset height of $0.5 \mathrm{~m}$ to males at the lek to approximate their height more closely. We also adjusted both the search radius and observer offset to model how the visual acuity and behavior of different observers affected viewshed area (see below). Visibility was determined using the 'visibility' function in the ArcView's Spatial Analyst Extension. For each lek, we converted the total number of cells visible to at least one male to $\mathrm{km}^{2}$.

\section{Visibility Analyses}

We analysed visibility from the perspective of (1) a golden eagle searching for a lek from the ground, (2) a female sage grouse searching visually for the lek from the ground, (3) an eagle searching from the air at various altitudes and (4) a male sage grouse on the lek scanning for a flying eagle. For each scenario, we assumed a visual target diameter $(d)$ and level of visual acuity (minimum resolvable angle $\alpha$ ) that defined the maximum range $(r=d / 2 \times \tan (\alpha / 2))$ at which the target was barely detectable. This set the search radius for viewshed estimation. We assumed that a distant observer viewing the lek would detect the elliptical 'tar- 
(a)

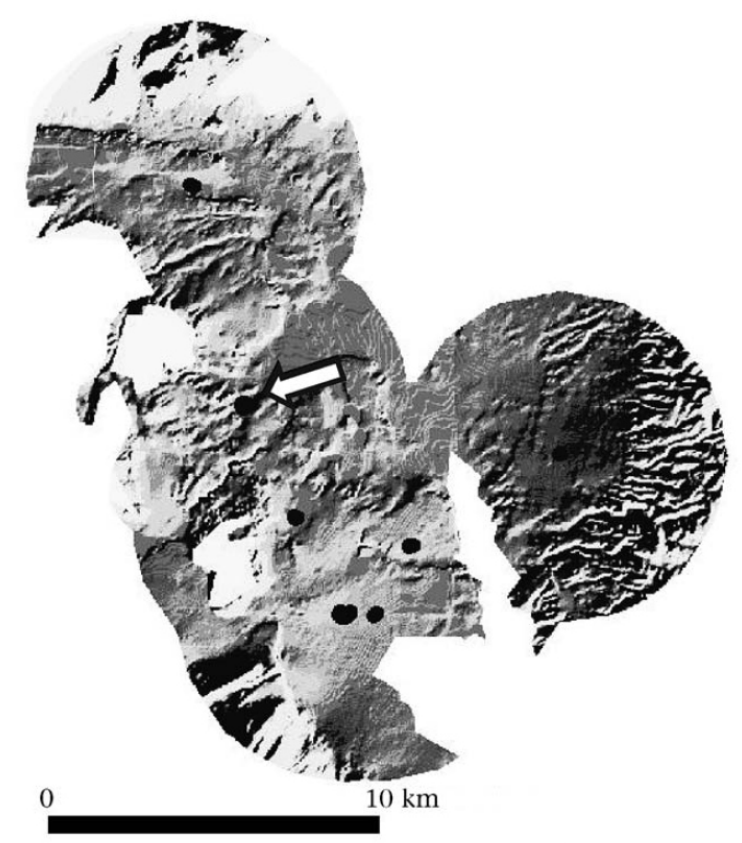

(b)

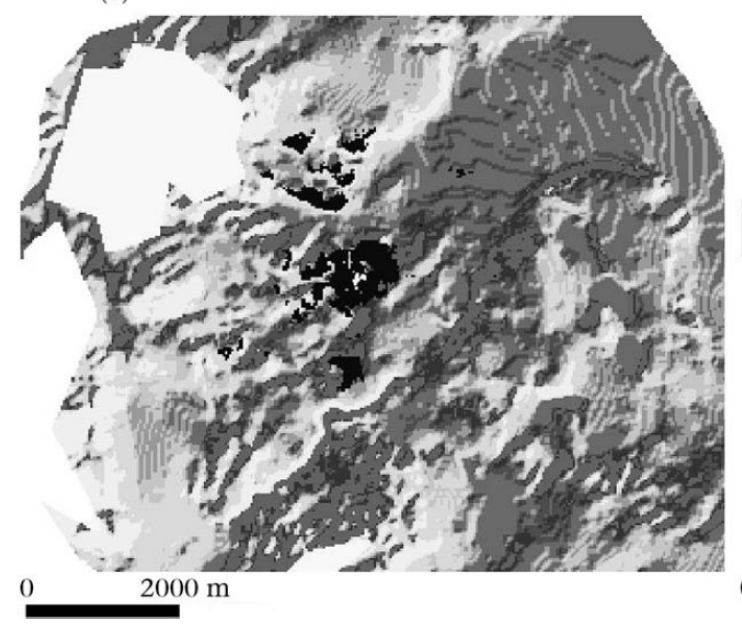

(c)

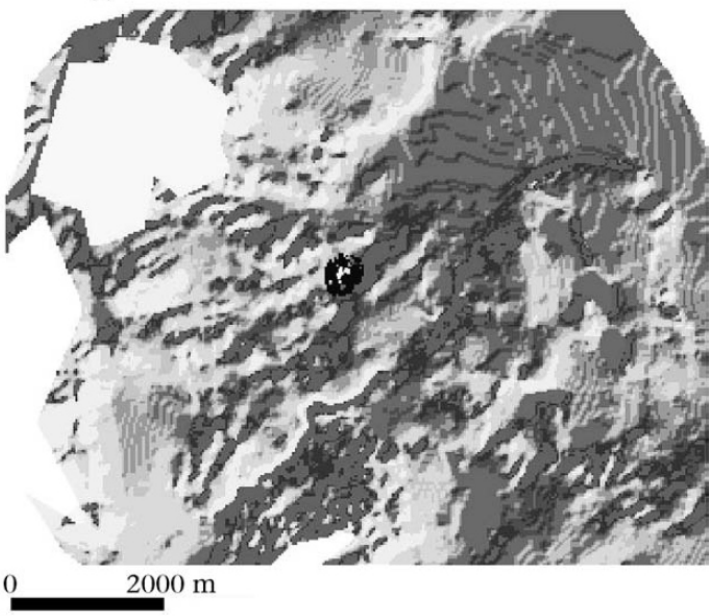

Figure 1. (a) Leks (filled circles represent displaying males) active in April 2001. The white arrow indicates lek LV 8. (b) The area visible up to $2 \mathrm{~km}$ from displaying males from lek LV 8 (black). (c) The area visible up to $200 \mathrm{~m}$ from displaying males from lek LV 8 (black), superimposed on a terrain model of Long Valley, California.

get' of white feathers formed by a displaying male's breast and neck, which contrasts sharply with both the male's mostly cryptically coloured plumage and the lek substrate. We estimated the maximum diameter of this area $(0.27 \mathrm{~m})$ from photos of a displaying banded male of known wing dimensions. For male grouse viewing a flying golden eagle, we used the latter's wingspan (2 m, Watson 1997) as the target diameter. To estimate visual acuity, we used values derived from achromatic visual contrast sensitivity functions, assuming maximal contrast between a target and its surroundings (Hodos 1993). Because visual acuity has apparently not been measured for the golden eagle, we used data from the similarly sized and congeneric wedge-tailed eagle, $A q$ uila audax (compiled in Hodos 1993). In the absence of equivalent psychophysical data for sage grouse or a close relative, we used a value for the well-studied domestic pigeon, Columbia livia (Hodos 1993). These data predict maximum visual detection distances of approximately 2,000 $\mathrm{m}$ for an eagle searching for displaying sage grouse, $200 \mathrm{~m}$ for a female sage grouse searching for a male, and 1,450 $\mathrm{m}$ for a sage grouse scanning for a flying eagle. To check the robustness of our conclusions, we also computed lek visibilities to groundbased observers at several distances between 200 and 2,000 $\mathrm{m}$ and also with no detection distance restriction within the area mapped in Figure 1 (see Results).

To examine the visibility of leks to flying eagles and of a flying eagle to sage grouse, we analysed eagle offset heights of 5, 10 and $50 \mathrm{~m}$. The former values were 
chosen after computing how the average area visible within a search radius of 2,000 $\mathrm{m}$ from random locations in Long Valley changed with altitude. The first two values cover a region in which the visible area increases rapidly with elevation, whereas at $50 \mathrm{~m}$, the entire area within the detection radius is usually visible.

For each viewing scenario, we compared the visibility of each lek site to the average visibility of 10 'random leks' with the same configuration of males but centred on randomly generated sites. We generated a different set of 10 random leks for each of the seven real leks. To ensure that random leks fell within areas used by females at this time of year, and thus, in areas favored by lekking males (Gibson 1996), we constrained their locations to fall within 3,000 m of an active lek. All random lek viewsheds fell within the area mapped in Figure 1 . We then compared the visibility of the real leks to the mean visibility of the matched set of random leks using a Wilcoxon matched-pairs signed-ranks test. We chose this test because differences between areas visible from real and random leks were not normally distributed. When interpreting statistical test results, we treated each of the four viewing scenarios as independent null hypotheses. Therefore, for each scenario involving a flying eagle ( 3 and 4 ), we Bonferroni-adjusted $a_{\text {crit }}$ across the three elevations tested to maintain the overall alpha at 0.05 . All statistical tests are two tailed.

\section{RESULTS}

The visibility of leks differed significantly from random sites in two ways (Table 1). First, from the perspective of a golden eagle scanning for lekking males from the ground (radius 2,000 $\mathrm{m}$, observer offset 0.5 $\mathrm{m})$, leks were visible over an average area that was one-third smaller than that of random sites. Conversely, for a female searching visually for a lek (radius 200 $\mathrm{m}$, offset $0.5 \mathrm{~m}$ ), leks were visible over a $20 \%$ larger area than those of random sites. For the latter analysis, none of the random lek viewsheds overlapped deleted habitat (see Methods) where inclusion could otherwise have produced a bias favoring this result.
Because the actual limits of visual detection for each species are uncertain (see Discussion), we checked the robustness of these patterns by comparing lek and random lek visibilities at several distances between 200 and 2,000 $\mathrm{m}$ (Figure 2). Interpolation from fitted leastsquares polynomial regressions indicated that leks were more visible than random sites below $879 \mathrm{~m}$ and less visible at greater distances. Tests at sampled distances (Figure 2) indicated that leks were more visible than random sites at least up to $250 \mathrm{~m}$, but were statistically indistinguishable at 500 and $1,000 \mathrm{~m}$. The two curves diverged rapidly above $1,000 \mathrm{~m}$, suggesting that the leks fell below random site visibility well below 2,000 $\mathrm{m}$. In addition, leks were significantly less visible than random sites when the radius of detection was unrestricted within the area mapped in Figure 1, which imposed 5,000-m boundaries around each lek $\left(\bar{X} \pm\right.$ SE: $30.8 \pm 6.1$ versus $69.5 \pm 4.8 \mathrm{~km}^{2}$; Wilcoxon matched-pairs signed-ranks test: $T=0, N=7, P=$ $0.016)$. In short, male sage grouse selected display sites where surrounding topography both enhanced shortrange visibility $(<500 \mathrm{~m})$ and diminished long-range visibility $(>1,000 \mathrm{~m})$ to ground observers.

Males might select sites for both characteristics. Alternatively, because leks are often situated in low points surrounded by hills (Wiley 1973), the two might be topographically linked so that choice for short-range visibility necessarily reduces long-range visibility and vice versa. To evaluate this, we examined the relation between 200- and 2,000-m radius visibility among the 70 random leks, using a repeated measures model (Littell et al. 1996) to control for variation in lek area. Offset heights for both male grouse and observer were set at $0.5 \mathrm{~m}$. We found no relation between visibility at these two scales $\left(F_{1,6}=0.00, P=0.996\right)$, suggesting that these characteristics are not linked and, therefore, that males select for both when choosing a display site.

For flying eagles, topography had no statistically detectable effect on lek visibility regardless of elevation (radius 2,000 m; observer offsets 5,10 or $50 \mathrm{~m}$ ). Visibilities of actual leks averaged slightly, although not significantly, above those for random sites. Similarly,

Table 1. Visibility $\left(\bar{x} \pm \mathrm{SE} \mathrm{km}^{2}\right)$ from seven active sage grouse leks versus nonlek sites with the same geometric configuration of displaying males

$\begin{array}{lccccccc}\text { Scenario } & \text { Offset }(\mathrm{m}) & \text { Radius }(\mathrm{m}) & \text { Real leks } & \text { Random leks } & T & \mathrm{a}_{\text {crit }} & P \\ \text { Eagle to lek } & 0.5 & 2,000 & 2.35 \pm 0.54 & 3.54 \pm 0.43 & 1 & 0.05 & 0.021 \\ \text { Female to lek } & 0.5 & 200 & 0.16 \pm 0.02 & 0.13 \pm 0.02 & 2 & 0.05 & 0.046 \\ \text { Eagle to lek } & 5 & 2,000 & 6.99 \pm 1.09 & 6.65 \pm 0.67 & 12 & 0.017 & 0.813 \\ & 10 & 2,000 & 8.52 \pm 1.08 & 8.39 \pm 0.66 & 13 & 0.017 & 0.938 \\ & 50 & 2,000 & 12.07 \pm 0.38 & 10.81 \pm 0.84 & 4 & 0.017 & 0.109 \\ \text { Lek to eagle } & 5 & 1,450 & 4.74 \pm 0.62 & 3.84 \pm 0.23 & 5 & 0.017 & 0.156 \\ & 10 & 1,450 & 5.54 \pm 0.54 & 5.00 \pm 0.37 & 8 & 0.017 & 0.375 \\ & 50 & 1,450 & 6.96 \pm 0.16 & 6.40 \pm 0.30 & 1 & 0.017 & 0.021\end{array}$

Offset: height in meters added to all grid cells in the DEM outside the lek; Radius: outer spatial extent of the analysis in metres. T: Wilcoxon test statistic. Statistically significant test results (after Bonferroni adjustment where appropriate) are in bold type. 


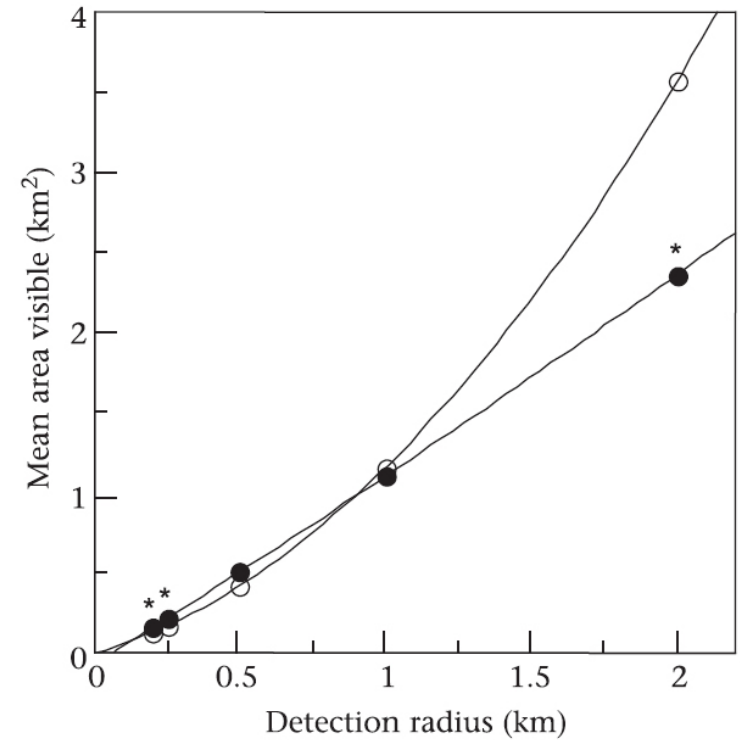

Figure 2. Mean areas over which real (filled circles) and random leks (open circles) were visible to observers on the ground (offset height $0.5 \mathrm{~m}$ ) within different radii of detection. Asterisks indicate significant differences between real and random lek means $(P<0.05$, Wilcoxon matched-pairs signed-ranks tests). Plotted curves are leastsquares second-degree polynomial regressions.

from the perspective of a grouse at the lek (radius 1,450 $\mathrm{m}$, observer offsets 5,10 and $50 \mathrm{~m}$ ), the area over which a flying eagle was visible from real leks averaged slightly above that for random sites. After Bonferroni adjustment, none of the differences was significant.

\section{DISCUSSION}

Our analyses show that sage grouse males lek at sites that both enhance their short-range visibility and decrease their long-range visibility to ground-based observers relative to random sites in the same area. This pattern reflects the typical siting of leks in dips bounded at a distance of several hundred metres by low hills (Wiley 1973; Bradbury et al. 1989b) and suggests that male sage grouse respond to these relatively large-scale topographic features when selecting display sites.

Topographic characteristics of leks may substantially decrease the area over which displaying grouse would be visible to perched golden eagles (Table 1). This conclusion rests on our estimates of maximal detection distance, which neglects several factors, including low ambient light levels and atmospheric attenuation that could decrease detection distance. However, unless these factors halved the distance at which an eagle can detect displaying sage grouse, our conclusion would not be affected (Figure 2). Because eagles often hunt from the air (Watson 1997) and lek topography does not affect visibility to aerial observers, reduced lek visibility from the ground need not reduce encounters with this predator. However, reduced lek visibility may force eagles to monitor lek activity from the air and thus, to more often reveal themselves to their prey at long range. Flying eagles are likely to be more visible to grouse for several reasons, including increased apparent size, contrast and movement, all of which elevate avian visual detection in psychophysical tasks (Hodos 1993).

Enhanced short-range visibility is of potential importance in at least two contexts. First, it may increase visibility of males to females in the immediate vicinity of the lek, although this conclusion is subject to the reliability of our assumptions about the visual acuity of these birds. Longer-range attraction of females presumably relies more on acoustic signalling, which is easily detectable by human observers at ranges beyond $200 \mathrm{~m}$, including at sites from which the lek cannot be observed directly (unpublished observations). Long-range acoustic signalling is also implicated by other observations, including (1) the propensity of males to display at times when acoustic conditions for signal propagation are most favorable but low light intensity renders visual signals ineffective (Dantzker et al. 1999), and (2) the crepuscular timing of peak female arrival at leks (Gibson \& Bachman 1992; Boyko et al. 2004). Enhanced short-range visibility immediately around the lek could also serve an antipredator function by allowing males to monitor their immediate surroundings more effectively. This might be particularly important in evading low-level eagle attacks that cannot be detected at longer range due to poor light and a raptor's contour-hugging approach (Wiley 1973).

Other lek characteristics, including the spectral properties of the substrate and the aspect with respect to the rising sun, are potentially relevant to the visibility of sage grouse lek display. Although the former is beyond the scope of our analysis, pilot analyses revealed no difference in mean aspect between leks and random sites, suggesting that this is not a relevant issue (A.S. Aspbury, unpublished data).

Although we have argued that sage grouse select leks with topographic features that enhance visual predator detection and short-range mate attraction, other factors correlated with visual aspects of topography may provide alternative or additional explanations for these patterns. For example, sage grouse typically lek in areas with little brushy vegetation, perhaps because this impedes short-range visual communication and can conceal ambush predators (R.M. Gibson, unpublished data). In our study area, leks are typically in meadows, which occur in lower-lying areas (Gibson 1996). Another more speculative possibility is that males select display sites favorable for long-range acoustic signal propagation, which is facilitated either 
by preferred lek topography or by correlated surface features. However, although other acoustically signalling animals respond adaptively to local environmental features affecting acoustic signal propagation (Lardner \& bin Lakim 2002), we are not aware of evidence for effects operating at the large spatial scale analysed here. Regardless of the merit of these additional hypotheses, the topographic characteristics of leks have unavoidable consequences for short-and long-range visibility to ground observers that are of potential adaptive significance.

In conclusion, sage grouse select display sites where topography affects their long-range visibility to terrestrial observers. These results suggest that, in open habitats, visually signalling animals may exploit local topography to control both their visibility to receivers and the visibility of their immediate surroundings. Our methods provide a basis for investigating this idea further in other systems.

\section{Acknowledgments}

NSF grant IBN-0078013, a Suzanne O. Prather Memorial Scholarship and a Graduate Studies Day Fellowship from the University of Nebraska, Lincoln, supported data collection. We thank Steve Nelson for the digital elevation model of Long Valley, Mark Chappell for photographing male Red-Yellow-Red, Dan Dawson and the University of California Natural Reserve System for logistical support, and Caitlin Gabor and two anonymous referees for helpful comments on the manuscript.

\section{References}

Andersson, M. 1994. Sexual Selection. Princeton, New Jersey: Princeton University Press.

Boyko, A.R., R.M. Gibson, and J.R. Lucas, 2004. How predation risk affects the temporal dynamics of avian leks: sage grouse vs. golden eagles. American Naturalist 163: 154-165.

Bradbury, J. W. \& Vehrencamp, S. L. 1998. Principles of Animal Communication. Sunderland, Massachusetts: Sinauer.
Bradbury, J. W., Vehrencamp, S. L. \& Gibson, R. M. 1989a. Dispersion of displaying male sage grouse. 1. Patterns of temporal variation. Behavioral Ecology and Sociobiology 24: 1-14.

Bradbury, J.W., R.M. Gibson, C. McCarthy, and S.L. Vehrencamp, 1989b. Dispersion of displaying male sage grouse. 2. The role of female dispersion. Behavioral Ecology and Sociobiology 24: 15-24.

Candolin, U., and H. Voight, 1998. Predator induced nest site preference: safe nests allow courtship in sticklebacks. Animal Behaviour 56: 1,205-1,211.

Dantzker, M.S., G.B. Deane, and J.W. Bradbury, 1999. Directional acoustic radiation in the strut display of male sage grouse Centrocercus urophasianus. Journal of Experimental Biology 202: 2,893-2,909.

Endler, J.A., and M. Théry, M. 1996. Interacting effects of lek placement, display behavior, ambient light, and color patterns in three neotropical forest-dwelling birds. American Naturalist 148: 421-452.

Gibson, R.M. 1996. A reevaluation of hotspot settlement in lekking sage grouse. Animal Behaviour 52: 993-1005.

Gibson, R.M., and G.C. Bachman, 1992. The costs of female choice in a lekking bird. Behavioral Ecology 3: 300-309.

Hartzler, J.E. 1974. Predation and the daily timing of sagegrouse leks. Auk 91: 532-536.

Heindl, M. \& Winkler, H. 2003. Interacting effects of ambient light and plumage color patterns in displaying wire-tailed manakins (Aves: Pipridae). Behavioral Ecology and Sociobiology, 53: 153-162.

Hodos, W. 1993. The visual capabilities of birds. In: H.P. Zeigler and H.J. Bischof, editors, Vision, Brain and Behavior in Birds, pp. 63-76. Cambridge, Massachusetts: MIT Press.

Lardner, B., and M. bin Lakim, 2002. Tree-hole frogs exploit resonance effects. Nature, 420, 475.

Littell, R.C., G.A. Milliken, W.W. Stroup, and R.D. Wolfinger, 1996. SAS System for Mixed Models. Cary, North Carolina: SAS Institute.

Watson, J. 1997. The Golden Eagle. London: T. \& A. D. Poyser.

Wiley, R.H. 1973. Territoriality and non-random mating in sage grouse, Centrocercus urophasianus. Animal Behaviour Monographs 6: 87-169.

Zuk, M. \& Kolluru, G. R. 1998. Exploitation of sexual signals by predators and parasitoids. Quarterly Review of Biology 73: 415-438. 